\title{
Pharmacological Screening of Cassia alata Leaves on Colorectal Cancer
}

\author{
Kudatarkar NM* and Nayak YK
}

Manipal College of Pharmaceutical Sciences, Department of Pharmacology, Manipal University, Karnataka, India

*Corresponding author: Namit Madan Kudatarkar, Manipal College of Pharmaceutical Sciences, Manipal University, Karnataka 576104, India, Tel: 9552880153; E-mail: namit.kudtarkar@gmail.com

Received date: March 07, 2018; Accepted date: March 14, 2018; Published date: March 19, 2018

Citation: Kudatarkar NM, Nayak YK (2018) Pharmacological Screening of Cassia alata Leaves on Colorectal Cancer. Colorec Cancer. Vol.4 No. 1:02.

Copyright: (ㄷ 2018 Kudatarkar NM, et al. This is an open-access article distributed under the terms of the Creative Commons Attribution License, which permits unrestricted use, distribution, and reproduction in any medium, provided the original author and source are credited.

\section{Abstract}

Background: The prevalence rate for colorectal cancer is found to be $9 \%$ worldwide. Studies have found out that people in developed western countries are more prone to colorectal cancer due to their low fiber food habits and sedentary life-styles. Herbal medicines, thus plays an important role in treatment of colorectal cancer. Cassia alata is one such plant having constituents like quercetin, Chrysoeriol etc. which has found to have anticancer activity.

Methods: Ethanolic extraction of Cassia alata leaves was carried out using Soxhlet apparatus and extract was standardized. Acute toxicity was carried out according to OECD guidelines. In in vivo studies, colorectal cancer was induced by administering Dimethyl hydrazine (DMH) intraperitoneally to male wistar rats for 20 weeks. Aberrant crypt foci count, colon length by weight ratio, liver index hematological and histological markers were the noted parameters.

Results: Cassia alata extract(CAE) was standardized by HPTLC. Upon oral administration of $2 \mathrm{~g} / \mathrm{kg}$, Cassia alata leaves extract (CAE) to female rats, mortality was not observed, and animals did not show any signs and symptoms of toxicity. Upon treatment for four weeks the rats did not show any cumulative toxicity profiles. Hematological parameters showed significant differences between the groups. In ACF count and colon length by weight ratio, there was significant difference found. In histopathological examination, it was found that there was formation of dysplasia in Standard and Posttreatment and malignancy was found in disease control and co-treatment group.

Conclusion: DMH produced tumors in the rats and by histopathological examination, it was found that Cassia alata leaves extract was not able to reduce inflammation and dysplasia. So, considering the findings from the present study, it can be concluded that ethanolic extract of Cassia alata leaves has failed to reduce tumors in $\mathrm{DMH}$ induced colorectal cancer model.
Keywords: Colorectal cancer; DMH; Cassia alata; Tumor

\section{Introduction}

Cancer is a disease that has been caused worldwide and mainly caused by the abnormalities caused due to mutation. Tumor are classified as two types namely benign and malignant. Benign tumor is the starting stage of cancer and remains confined to its original position whereas, malignant tumor means the cancer has occupied the cells and surrounding tissues. Benign tumors do not invade surrounding tissues and other body site. Malignant tumors are capable of metastasizing and invading surrounding tissues through circularly or lymphatic system. The capacity of dedifferentiation, invasiveness and metastasis determine severity of cancer.

Colorectal cancer is the 3rd most common cancer worldwide and 4th most common cause of death. Prevalence is $9 \%$ of cancer incidences. Growing problem is seen in developed countries with a western culture. Studies have found out that people in developed western countries are more prone to colorectal cancer due to their low fiber food habits and sedentary life-styles. Nowadays, there is a steady rise in incidences among developing countries such as India, due to westernization lifestyle, food and beverages. Though the diet, exercise and the healthy life style reduce the incidences of colorectal cancer the genetic and epigenetic changes due to environmental exposure cannot be neglected in the pathogenesis of colorectal cancer. Specific anticancer drugs have limitations due to multi-organ toxicities. Hence, alternative or herbal therapy is playing important role.

Cassia alata (Fam: Caesalpiniaceae) is one such plant widely used plant in traditional medicine [1]. This plant leaves are reported for phenolics and cytotoxic activity. Cassia alata is a shrub with thick downy branches, which is found almost throughout India. Leaflets are 8-12 pairs, lower leaflet oblongelliptic; upper ones broadly obovate. It is also known as Ringworm shrub and winged Senna in English. In Indian systems, the leaves of the plant are used as purgative, expectorant, astringent, vermicide and to treat all skin 
diseases. The major chemical constituents are Chrysoeriol, kaempferol, quercetin, 5,7,4'-trihydroflavanone,17hydrotetratriacontane, palmitic acid, stearic acid etc. Most of these chemicals are reported to have anti-inflammatory, antiarthritis [2] and cytotoxicity activity against lung cancer [3]. Thus Cassia alata leaves extract could be better alternative for treatment and prevention of colorectal cancer.

From a thorough literature review we found that this plant leaves are not being screened for colorectal cancer though it has many phytoconstituents which are reported for colorectal cancer. Hence, we took this plant leaves for thorough investigation for its benefits in $\mathrm{DMH}$-induced rat colorectal cancer.

\section{Materials and Methods}

\section{Collection and extraction of Cassia alata leaves}

The collected leaves were air-dried at room temperature for 6-10 days. Upon drying, the plant materials were grinded into smaller particles into fine powder using mixer. The powdered samples were then stored in airtight containers and kept at room temperature until required (Tables 1 and 2).

Table 1 Equipment's and suppliers.

\begin{tabular}{|c|c|}
\hline Equipment & Company \\
\hline Autoclave & Oswald, India \\
\hline Automated blood cell counter & ERMA Inc, Tokyo \\
\hline Deep freezer & Electrolux, India \\
\hline Electronic balance & Sartorius, Germany \\
\hline Elisa plate reader & Biotek, USA \\
\hline Hot air oven & Oswald, India \\
\hline Laminar air flow & Labline, India \\
\hline Micropipettes & Thermo scientific, USA \\
\hline Milli Q & Millipore \\
\hline $\mathrm{pH}$ meter & Systronic, India \\
\hline Compound microscope & Olympus, USA \\
\hline Sonicator & Polytron, USA \\
\hline Tissue homogenizer & Remi, India \\
\hline 96 well plates $\{$ sterile $\}$ & Greiner bio-one, Germany \\
\hline Aluminum foil & Diamond, India \\
\hline Centrifuge tubes & Tarsons, India \\
\hline Syringes & BD bioscience \\
\hline
\end{tabular}

The powdered leaves were then subjected to Soxhlet extraction with ethanol for an average of 20 cycles of complete extraction. The extract was then collected in round bottom flask and concentrated by vacuum distillation method using rotavapor instrument. The final concentrate of the extract was freeze dried and lyophilized. The final lyophilized semisolid
Cassia alata leaves extract (CAE) was then preserved in desiccator for complete dryness till further use [4] (Figure 1).

Table 2 Chemicals and suppliers.

\begin{tabular}{|l|l|}
\hline Chemical & Company \\
\hline Dimethyl hydrazine & Sigma Aldrich, USA \\
\hline Disodium hydrogen phosphate & Sisco research lab pvt Itd, India \\
\hline DMSO & Merck and co, Inc, India \\
\hline Ethanol & SD fine chemicals, India \\
\hline Potassium hydroxide & Nice chemicals \\
\hline Sodium dihydrogen phosphate & Sisco research lab pvt Itd, India \\
\hline DMEM & HI media, India \\
\hline 5-Fluorouracil & Gibco-Invitrogen, USA \\
\hline MTT & Sigma Aldrich, USA \\
\hline EDTA & Gibco-Invitrogen, USA \\
\hline
\end{tabular}

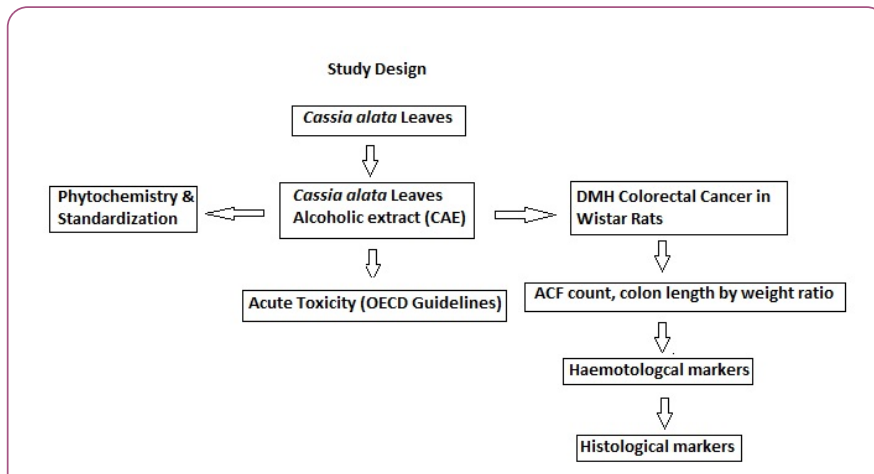

Figure 1 Study design of Cassia alata.

\section{Phytochemical test for active constituents in extract-CAE}

The extract-CAE was tested for different phytoconstituents such as Alkaloid test (Dragendroff's test), Flavonoids test, Saponins test (Foam test), Tannins (Lead acetate test), Glycosides (Molisch's test), Carbohydrates (Benedicts test), Phenols (Ferric chloride test), Proteins (Xanthoproteic test), Amino acid (Ninhydrin test) as per the literature (Trease Evan's text book).

\section{Standardization of extract-CAE by HPTLC}

\section{Instrument: CAMAG LINOMAT 5 with CAMAG SCANNER 3}

Stationary phase: HPTLC silica gel GF 254 pre-coated layer (10 $\mathrm{cm} \times 10 \mathrm{~cm}$ )

Mobile phase: Toluene: Ethyl acetate: Formic acid:(5:4:0.2)

Standard: Quercetin

Sample: Green semisolid

Solubility: Methanol 
Standard concentration: $4 \mu \mathrm{L}$

Sample concentration: 4 and $8 \mu \mathrm{L}$

Detection wavelength: $254 \mathrm{~nm}, 366 \mathrm{~nm}$ and $540 \mathrm{~nm}$.

Procedure: Applied $4 \mu \mathrm{L}$ of standard solution and $4,8 \mu \mathrm{L}$ of test solution on a percolated silica gel $60 \mathrm{GF}_{254}$ TLC Plate of uniform thickness $0.2 \mathrm{~mm}$ using sample applicator. Developed the plate in the solvent system to a distance of $6 \mathrm{~cm}$. Scanned the plate densitometrically at 254, 366 and $540 \mathrm{~nm}$ using TLC Scanner. Observed the plate under UV light at $254 \mathrm{~nm}$ and 366 nm using Camag Scanner 3.

\section{In vivo animal studies}

Animals used: Inbred male Wistar rats from Central Animal Research Facility, Manipal University, India. Rats were acclimatized in the experimental room maintaining temperature at $23 \pm 3{ }^{\circ} \mathrm{C}$, with controlled humidity conditions $75 \%$, and light and dark cycle of 12:12 hours. Housing of rats were done in sterile polypropylene cages which contained bedding materialize. sterile paddy husk. The animals were fed on autoclaved rat feed and water. 8 to 10 weeks old male rats weighing $170 \pm 10$ grams were used for the study. Care and handling of animals was carried out in with respect to the guidelines issued by Institutional Animal Ethics Committee, Manipal University, Manipal, Karnataka, India (number IAEC/KMC/73/2016).

\section{Oral acute toxicity studies}

The acute oral toxicity studies are carried out as per OECD 425 guidelines. Female Wistar rats of 8 weeks old should be used. As per OECD 425 guidelines the limit test will be carried out with $2 \mathrm{~g} / \mathrm{kg}$ p.o. dose in one animal at a time followed by three animals on each $24 \mathrm{~h}$ gap. The animals will be observed for lethality or any other type of acute toxicity on cage side observation for 72 hours. Maximum of 20 rats will be used for the study as the leaves were proposed to be nonlethal as they are edible to humans [5].

\section{Induction of colorectal cancer by $\mathrm{DMH}$ and treatment with $\mathrm{CAE}$}

The colorectal cancer in rats was induced by administration of $\mathrm{DMH}$ at a dose of $20 \mathrm{mg} / \mathrm{kg}$, i.p., for first 10 weeks and then for next 10 weeks as per the literature. After 10th week of $\mathrm{DMH}$-administration the induction of aberrant crypt foci (ACFs) was confirmed by methylene blue staining. The rats were then randomized according to body weight and treatments started (as shown in Table 3).

The standard control group rats received 5-FU (weekly 10 $\mathrm{mg} / \mathrm{kg}$, i.p.) along with $\mathrm{DMH}$, from 10 th week of $\mathrm{DMH}-$ induction. The rats in the group $\mathrm{CAE}$-cotreatment received an oral dose of $200 \mathrm{mg} / \mathrm{kg}$, after 10th week along with DMHinduction for 10 weeks. The CAE-post-treatment group received oral dose of CAE $200 \mathrm{mg} / \mathrm{kg}$, after 20 weeks of $\mathrm{DMH}$ induction for another three weeks. The treatment planner is represented diagrammatically in Figure 2 ). The normal control received $0.5 \% \mathrm{CMC}(0.1 \mathrm{~mL} / 100 \mathrm{~g}$, p.o.). After sacrificing the rats, the colon tissue was observed for ACFs, adenoma, and adenocarcinoma as per the standard protocol.

To study the cumulative effect of extract-CAE one group of rats $(n=6)$ received oral dose of CAE $200 \mathrm{mg} / \mathrm{kg}$ for four weeks. The toxic effect of CAE upon accumulation in body was observed in these rats.

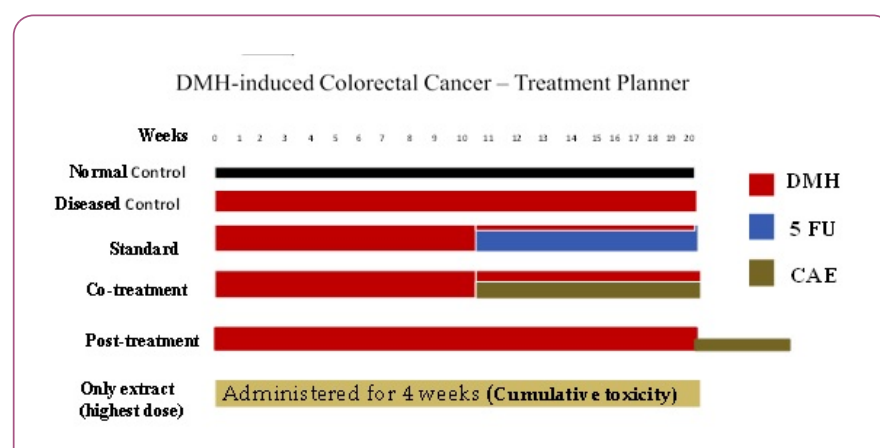

Figure 2 Dosage regimen for $\mathrm{DMH}$-induced colorectal cancer and treatment planner.

Table 3 DMH: Dimethylhydrazine; 5-FU: 5-flurouracil; CAE: Cassia alata leaves extract; Co-treatment: treatment with $\mathrm{CAE}$ after 10 weeks; Post-treatment: treatment with CAE after 20 weeks; $(n=6)$.

\begin{tabular}{|c|l|l|}
\hline $\begin{array}{l}\text { Group } \\
\text { no }\end{array}$ & Group name & Dosage \\
\hline 1 & Normal control & Saline $(0.1 \mathrm{~mL} / 100 \mathrm{~g}$, i.p. $)$ \\
\hline 2 & $\begin{array}{l}\text { DMH-induced } \\
\text { control }\end{array}$ & $\begin{array}{l}\text { DMH } 20 \mathrm{mg} / \mathrm{kg}, \text { i.p., for first } 10 \text { week, then } \\
30 \mathrm{mg} / \mathrm{kg}, \text { i.p., for } 20 \text { weeks }\end{array}$ \\
\hline 3 & Standard Control & DMH Induced+5-FU $(10 \mathrm{mg} / \mathrm{kg}$, i.p. $)$ \\
\hline 4 & Co-treatment & DMH-induced+CAE $(200 \mathrm{mg} / \mathrm{kg}$, p.o. $)$ \\
\hline 5 & Post-treatment & DMH-induced+CAE $(200 \mathrm{mg} / \mathrm{kg}$, p.o. $)$ \\
\hline
\end{tabular}

\section{Preparation of reagents and test samples}

DMH preparation: $\mathrm{DMH}$ was prepared freshly in $1 \mathrm{mM}$ EDTA-saline ( $\mathrm{pH}$ adjusted to 7 with $\mathrm{NaOH}$ ).

CMC preparation: CMC $0.5 \%$ suspension was prepared by mixing $500 \mathrm{mg} \mathrm{CMC} \mathrm{in} 100 \mathrm{~mL}$ distilled water.

Test samples (CAE and 5-FU) were suspended in $0.5 \% \mathrm{CMC}$ before administration.

\section{Parameters monitored in DMH model}

1) Hematological parameters,

2) Presence of Polyps count as ACF incidence,

3) ACF count,

4) Colon length/weight ratio,

5) Histopathological examination. 


\section{Hematological parameters}

The blood was withdrawn by retro-orbital puncture, just prior to the sacrificing the rats. The blood was collected in 2 $\mathrm{mL}$ Eppendorf tube with anticoagulant 0.5\% EDTA. The hematological parameter is determined by the animal-cell count analyzer.

Following parameters were tabulated and compared between the treatment groups- Total WBC count, Total RBC count, Hemoglobin content, Total platelet count, Percentage of lymphocytes, Monocytes and Granulocytes.

\section{Polyp count as ACF incidence}

The rats in each group were examined for ACF and incidence and was calculated as

\%of ACF incidence $=[$ No of rats with $A C F /$ No of rats examined] $\times 100$

\section{ACF count}

Colon segments were collected, opened longitudinally and flatly fixed on chart paper dipped in $10 \%$ buffered formalin. After 12 hours they were stained with $0.1 \%$ methylene blue in PBS for $5 \mathrm{~min}$ and distained with PBS. Specimens were observed under microscope (10X magnification) and ACF were counted and calculated as number $/ \mathrm{cm}^{2}$ and image were taken in microscope.

\section{Colon length/weight ratio}

Colon length/weight ratio=length of colon in $\mathrm{cm} /$ weight of colon in grams

\section{Liver index}

Liver were removed and weighed in grams.

Liver index=weight of liver in grams/body weight of animal in grams.

\section{Statistical analysis}

Data were analyzed using one-way analysis of variance (ANOVA). Significant differences amongst treatment groups were evaluated by Post Hoc Tukey's test. The results were considered significant at $P<0.05$. All statistical analyses were done using Prism 5.03 Demo Version (Graph Pad Software Inc., La Jolla, CA, USA).

\section{Results and Discussion}

\section{Phytochemistry and standardization}

The extract CAE was tested for different active constituents. The results of these tests are listed in Table 4. The extract-CAE showed the positive reaction for the presence of alkaloids, phenols, flavonoids, saponins, tannins and glycosides.

Table 4 Phytochemistry of Cassia alata extract (CAE).

\begin{tabular}{|l|l|l|}
\hline Sr no & Phytochemical Test & Ethanol extract \\
\hline 1 & Alkaloid test (Dragendroff test) & Present \\
\hline 2 & Flavonoids test & Present \\
\hline 3 & Saponins test (Foam test) & Present \\
\hline 4 & Tannins (Lead acetate test) & Present \\
\hline 5 & Glycosides (Molisch's test) & Present \\
\hline 6 & Carbohydrates (Benedicts test) & Present \\
\hline 7 & Phenols (Ferric chloride test) & Present \\
\hline 8 & Proteins (Xanthoproteic test) & Absent \\
\hline 9 & Amino acid (Ninhydrin test) & Absent \\
\hline
\end{tabular}

\section{Standardization of the extract-CAE by HPTLC}

Generally, the plant extract is standardized by HPLC and HPTLC method. In the present study it was planned to standardize the extract by HPTLC and analyze the peaks quantitatively. Literature review on the plant Cassia alata reports that the plant contains quercetin a common flavonoid. Hence, in the present study quercetin was taken as standard.

The extract CAE gave 11 different spots with $R_{f}$ ranging from 0.13 to 0.93 using the solvent system Toluene: Ethyl acetate: Formic acid:(5:4:0.2) at room temperature.

\section{Acute oral toxicity of CAE as per OECD guideline}

Toxicity studies was carried out as per OECD 425 guidelines. Upon oral administration of $2 \mathrm{~g} / \mathrm{kg}$, Cassia alata leaves extract (CAE) to female rats, mortality was not observed, and animals did not show any signs and symptoms of toxicity. Further observation for 14 days, the animals did not show any untoward effect on central nervous system, peripheral nervous system and other immunological reactions. and the result was that no toxicity has been seen. Based on the earlier literature and non-lethal effects in our acute toxicity studies, we have fixed a single therapeutic dose of $200 \mathrm{mg} / \mathrm{kg}$, p.o., for in vivo study in animal models.

\section{Cumulative toxicity of CAE on male rats}

The extract CAE was administrated to the rats for four weeks at the therapeutic dose $(200 \mathrm{mg} / \mathrm{kg})$ and observed for the cumulative toxicities. Upon treatment for four weeks the rats did not show any cumulative toxicity profiles such as gastrointestinal toxicity (defecation and constipation), urination, autonomic reflexes (like change in respiration heart rate, pupil size) and CNS related behavioral, motility and catatonic gate changes. 


\section{Hematological results of $\mathrm{DMH}$ induced rat colorectal model}
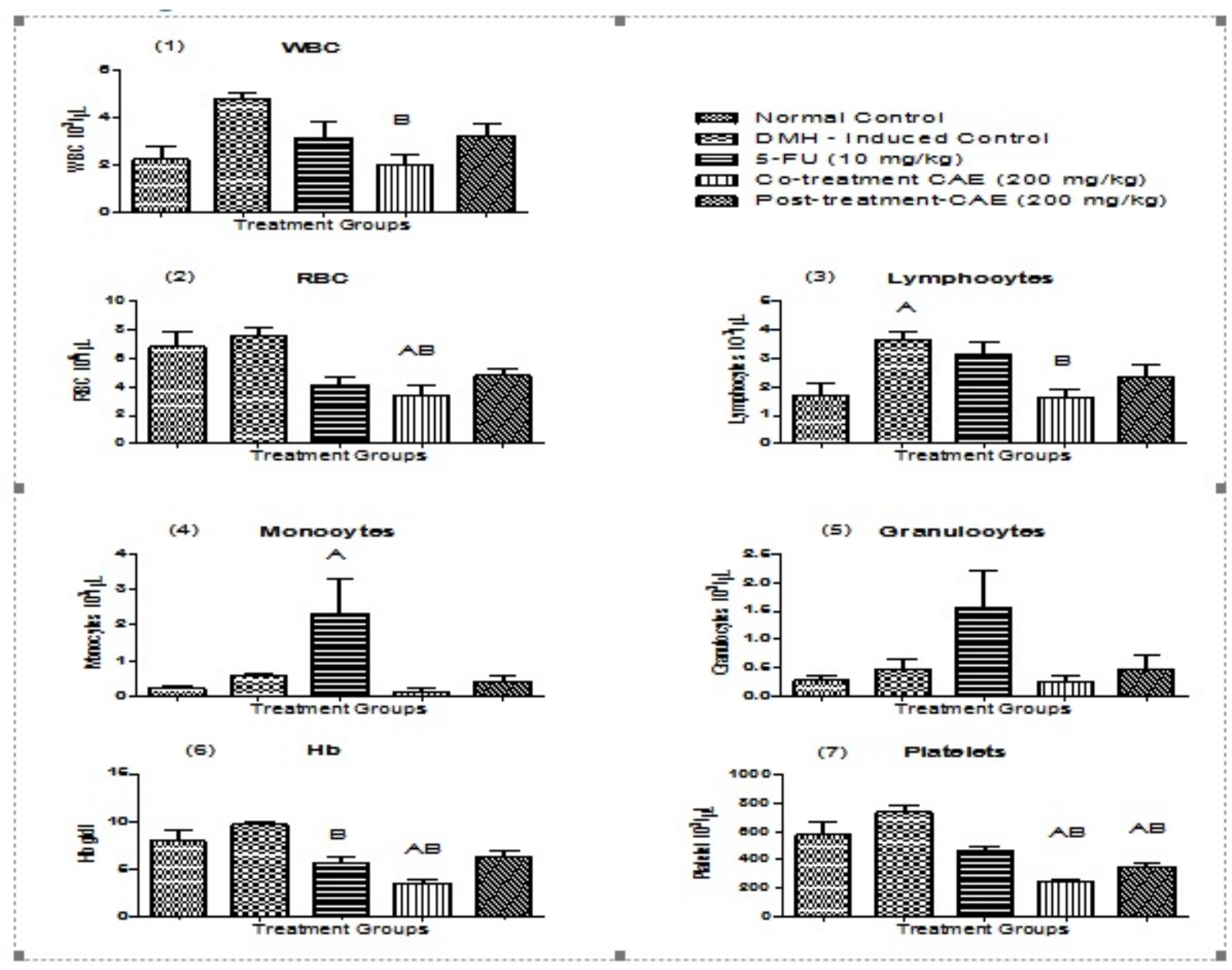

Figure 3 Effect of 5-FU and Cassia alata on (1) WBC (2) RBC (3) Lymphocytes (4) Monocytes (5) Granulocytes (6) Hgb (7) Platelets on $\mathrm{DMH}$ induced colorectal cancer.

By carrying out hematological parameters between the groups, it was found that the effect of extract- CAE showed significant differences in which the WBC level of CT group (cotreatment group) had decreased when compared to $\mathrm{DMH}$ induced control group. This means that the extract-CAE was able to neutralize the WBC level. There was a drastic decrease in the RBC level in the co-treatment group when compared to normal control and $\mathrm{DMH}$-induced control group. The

lymphocytes level increased in $\mathrm{DMH}$-induced control group and it was found that the extract-CAE in the co-treatment group was able to bring the lymphocyte level to normal.

\section{Effect of CAE on DMH-induced colorectal cancer}

Table 5 DMH: Dimethylhydrazine; 5-FU: 5-flurouracil; CAE: Cassia alata leaves extract; Co-treatment: treatment with CAE after 10 weeks; Post-treatment: treatment with CAE after 20 weeks; $(n=6)$.

\begin{tabular}{|l|l|l|l|}
\hline Treatment & No of rats examined & No of rats with ACF & ACF incidence (\%) \\
\hline Normal control & 6 & 0 & 100 \\
\hline DMH-control & 6 & 6 & 100 \\
\hline $5-F U$ & 6 & 6 & 100 \\
\hline CAE co-treatment & 6 & 6 & 100 \\
\hline CAE post-treatment & 6 & 6 & 100 \\
\hline
\end{tabular}


The monocytes level drastically increased in the 5-FU control group. There was no significant difference seen in granulocytes. The $\mathrm{Hb}$ level was found to be decreased in 5-FU group when compared to $\mathrm{DMH}$-induced group and there was also decreased $\mathrm{Hb}$ level in co-treatment group compared to normal and $\mathrm{DMH}$-induced control group. In platelet count, it has been found that both the co-treatment and the posttreatment had significant difference with the normal control and $\mathrm{DMH}$-induced control groups. There was decrease in the platelet level. By this, we can predict that the extract-CAE had toxicity that decreased platelet level (Figure 3 and Table 5).

\section{Effect of CAE on Colon length/weight ratio in DMH induced rat colorectal model:}

Colon length/weight ratio=[length in $\mathrm{cm} /$ weight in grams]

Table 6 The results of the ACF-count.

\begin{tabular}{|l|l|}
\hline Treatment & Colon length/weight ratio (mean \pm SEM) \\
\hline Normal control & $44.07 \pm 1.8$ \\
\hline DMH control & $13.77 \pm 1.36$ \\
\hline 5 -FU & $33.14 \pm 2.71$ \\
\hline CAE co-treatment & $25.58 \pm 1.53$ \\
\hline CAE post-treatment & $24.42 \pm 1.87$ \\
\hline
\end{tabular}

Effect of CAE on ACF count in DMH induced rat colorectal model: The ACF-count in the colon tissue is an important physical marker to score the induction of colorectal cancer in rats. The results of the ACF-count were tabulated in Table 6 and the comparison between the different treatment group was pictorially represented in Figure 4.

Table 7 Average determination of ACF count.

\begin{tabular}{|l|l|}
\hline Treatment & No of $\mathrm{ACF} / \mathrm{cm}^{2}$ (mean \pm SEM) \\
\hline Normal control & 0 \\
\hline DMH control & $4.5 \pm 0.56$ \\
\hline $5-F U$ & $2.5 \pm 0.22$ \\
\hline CAE co-treatment & $4 \pm 0.57$ \\
\hline CAE post-treatment & $3.5 \pm 0.76$ \\
\hline
\end{tabular}

The induction with $\mathrm{DMH}$ significantly increased the incidences and the ACF-count in colon mucosal tissue compared to the normal rats. Upon co-treatment and post treatment with extract-CAE at an oral dose of $200 \mathrm{mg} / \mathrm{kg}$ decreased the ACF-count but it was not significant compared to the induced control. Whereas, the treatment with 5-FU at dose of $10 \mathrm{mg} / \mathrm{kg}$, i.p., once a week, protected the colon tissue from incidences of ACF and total ACF-count (Table 7).

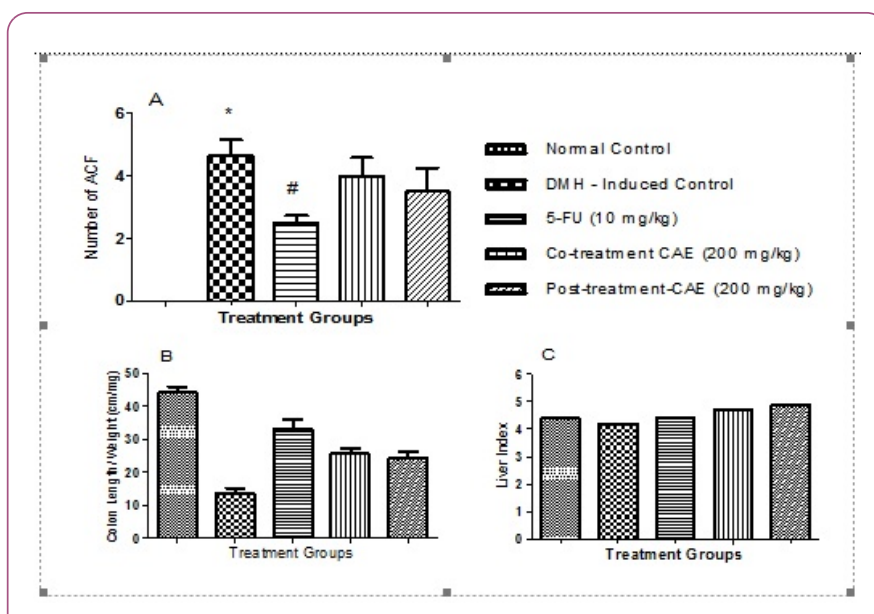

Figure 4 Effect of CAE on ACF count, Colon length/weight ratio and liver index in $\mathrm{DMH}$ induced rat colorectal model.

Histological examination of $\mathrm{DMH}$ induced rat colorectal cancer model: The infiltration of inflammatory cells to the damaged area is the one of the markers of cancer induction in rat colorectal cancer model. In the present study it was found a mild to moderate number of inflammatory cells infiltration to the mucosal area upon induction with $\mathrm{DMH}$. Though the infiltration of inflammatory cells is mild or moderate it is significant when it was compared to normal control. The chronic inflammatory cells like eosinophilic cell infiltration was mild in mucosa of colon in $\mathrm{DMH}$-induced rats and there were occasional proliferated lymphoid follicles. The whole colon was edematous and deposition of fibrin was observed in rats induced with $\mathrm{DMH}$. There were Hemosiderin layden macrophages, epithelial necrosis, desquamation, epithelial ulcers, hemorrhages, mucosal congestion are seen in mucosa as well as submucosa of colon in the rats induced with $\mathrm{DMH}$. Further there was hyperplasia and dysplastic changes in the mucosal epithelium was seen. These are the physical marker of induction of adenocarcinoma. Hence the $\mathrm{DMH}$ induced a condition of pre-malignancy symptoms in rats.

Upon co-treatment with extract CAE at an oral dose of 200 $\mathrm{mg} / \mathrm{kg}$ prevented most of the parameters such as infiltration of eosinophils, hemorrhages and the overall symptoms of premalignancy condition. These changes are comparable to that of standard 5-FU. Whereas, post-treatment with the extractCAE the reversal of the pre-malignancy condition was mild and not comparable to that of co-treatment and standard 5-FU (Figure 5). 


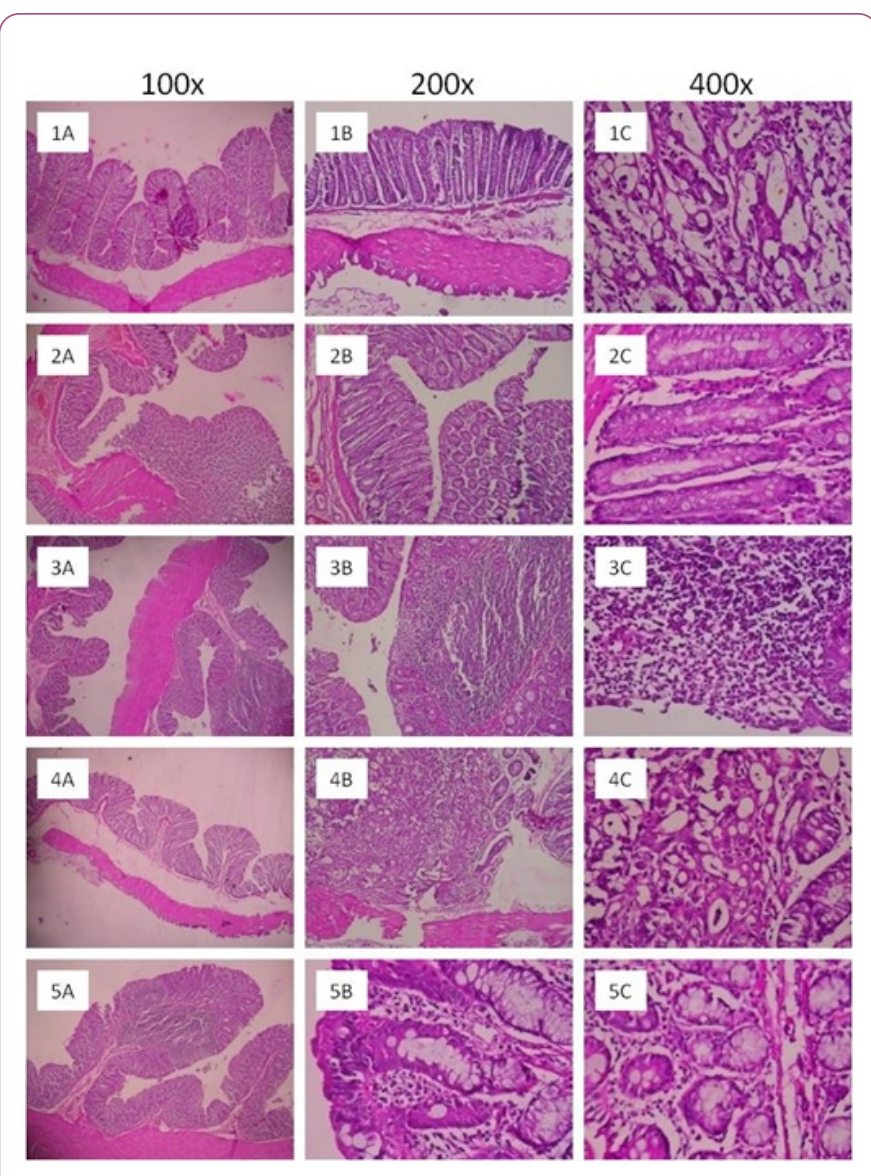

Figure 5 Histological examination of $\mathrm{DMH}$ induced rat colorectal cancer model at 100x, 200x, 300x.

\section{Discussion}

The objective of present study was to screen the anticancer potentials of the ethanolic extract of the Cassia alata leaves (CAE). The crude plant leaves were extracted with ethanol obtained a yield of $20 \mathrm{~g} \%$. The phytochemical screening revealed the presence of phenolics, flavonoids, alkaloids, saponins, tannins and carbohydrates.

Upon HPTLC analysis, the extract-CAE exhibited 11 different spots. These constituents can be further isolated in future studies.

Colorectal carcinogenesis is a multistep process that leads to the formation of $\mathrm{ACF}$, adenoma and carcinoma. $\mathrm{DMH}$ produces various metabolites and makes the mucosal DNA in the colon alkaline. AOM causes methylation at the 06 position of guanine in 6-12 hours of injection. In the present study, the parameters checked were ACF incidence, ACF count to check the extent of mucosal damage by $\mathrm{DMH}$.

There was significant difference in the colon length by weight ratio. The ratio was found to increase in co-treatment and post treatment group compare to $\mathrm{DMH}$ group. It did not show any significant effect on the liver index. In histopathological examination, it was found that there was formation of dysplasia in Standard and Post-treatment and malignancy was found in disease control and co-treatment group.

\section{Conclusion}

Based on the results by present experiments, we found that $\mathrm{DMH}$ produced tumors in the rats and by histopathological examination, it was found that Cassia alata leaves extract was not able to reduce inflammation and dysplasia formed due to $\mathrm{DMH}$.

So, considering the findings from the present study, it can be concluded that ethanolic extract of Cassia alata leaves has failed to reduce tumors in $\mathrm{DMH}$ induced colorectal cancer model.

\section{References}

1. World Cancer Research Fund and American Institute for Cancer Research (2007) Food, Nutrition, Physical Activity, and the Prevention of Cancer: A Global Perspective. Washington, DC: American Institute for Cancer Research.

2. Olarte El, Herrera AA, Villaseñor IM, Jacinto SD (2013) In vitro antitumor properties of an isolate from leaves of Cassia alata $\mathrm{L}$. 2Asian Pac J Cancer Prev 14: 3191-3196.

3. Lewis A, Levy A (2011) Anti-inflammatory activities of cassia alata leaf extract in complete freund's adjuvant arthritis in rats. West Indian Med J 60: 615-621.

4. Levy A, Lewis A (2011) Cassia alata leaf extract induces cytotoxicity in A549 lung cancer cells via a mechanism that is caspase 8 dependent. West Indian Med J 60: 608-614.

5. Prasad VG, Shishir K, Jayashree BS, Kumar NDR, Francis A, et al. (2014) Iminoflavones Combat 1,2-Dimethyl Hydrazine-Induced Aberrant Crypt Foci Development in Colon Cancer. BioMed Research International. 